\title{
MEASURING THE WELFARE GAIN FROM PERSONAL COMPUTERS
}

\author{
JEREMY GREENWOOD and KAREN A. KOPECKY*
}

\begin{abstract}
The welfare gain to consumers from the introduction of personal computers (PCs) is estimated. A simple model of consumer demand is formulated that uses a slightly modified version of standard preferences. The modification permits marginal utility, and hence total utility, to be finite when the consumption of computers is zero. This implies that the good will not be consumed at a high enough price. It also bounds the consumer surplus derived from the product. The model is calibrated/estimated using standard national income and product account data. The welfare gain from the introduction of PCs is 2\%-3\% of consumption expenditure. (JEL E01, E21, O33, O47)
\end{abstract}

\section{INTRODUCTION}

What is the welfare gain to consumers from the development of and improvements in personal computers (PCs)? This is the question addressed here. The answer offered is that welfare increased by somewhere between $2 \%$ and $3 \%$, measured in terms of total personal consumption expenditure, due to the introduction of the PC and its subsequent price decline. This finding is obtained by employing a model of consumer behavior, based upon more-orless standard preferences, which is fit to aggregate national income and product account data using a direct and simple calibration/estimation strategy.

To estimate the welfare gain from the introduction of a new product one must know what utility is in the absence of the good. A conventional isoelastic utility function has two problems. First, at zero consumption the utility function returns a value of minus infinity, whenever the elasticity of substitution is less than one. In this case the welfare gain from the introduction of the new good is infinitely large. Second, marginal utility at zero consumption is infinite, so long as the elasticity of substitution is finite. Therefore, consumers will

*The referee is thanked for a helpful suggestion and Mats Bergman is thanked for some inspiring comments.

Greenwood: Professor, Department of Economics, University of Pennsylvania, Philadelphia, PA 19104-6297. Phone 1-215-898-1505, Fax 1-215-746-2947.

Kopecky: Research Economist, Research Department, Federal Reserve Bank of Atlanta, 1000 Peachtree St. NE, Atlanta, GA 30309-4470. Phone 1-404-498-8974, Fax 1-404-498-8956, E-mail karen.kopecky@atl.frb.org always purchase some of the good in question, no matter how high the price is, albeit perhaps in infinitesimal quantities. To avoid these problems a form for preferences will be adopted that gives a finite level for marginal utility, and hence one for total utility, at zero consumption. With this utility function, high prices may result in the consumer optimally choosing to buy none of the new good. In addition, the consumer's surplus associated with the introduction of a new good is generally finite.

This paper contributes to the growing literature on measuring the welfare gains from new goods. A classic example is the work by Hausman (1999), who studies the introduction of cellular telephones. He finds that their tardy inclusion in the Consumer Price Index (CPI), some 15 years after their debut, results in a bias of up to $2 \%$ per year in the telecommunicationsservices price index. To obtain this estimate, Hausman (1999) effectively integrates back the estimated demand curve for cellular telephones to recover the indirect utility function for consumers. This function can be inverted to obtain the expenditure function, from which welfare measures can be calculated. The procedure was developed earlier in work by Hausman (1981).

\section{ABBREVIATIONS}

BEA: Bureau of Economics Analysis

BLS: Bureau of Labor Statistics

CPI: Consumer Price Index

GDP: Gross Domestic Product

PC: Personal Computer

RAM: Random-Access Memory 
Analytical solutions for the expenditure function can be obtained when the demand equation is (ln) linear. When the demand equation is not linear the indirect utility function may have to be recovered by numerically solving a differential equation. This procedure is dual to the one presented here, which focuses on the consumer maximization problem. Some utility functions, such as the one employed in the current work, may not lead to a linear demand equation of the form that is conventionally estimated.

Hausman (1999) also suggests an approximate measure of welfare based on a linear demand curve. While he states explicitly that this measure of welfare is a lower bound, this caveat is often forgotten in applied work. It may work well in the cell phone example that he studies. As illustrated in the PC example studied here, however, this approximate demand curve method can lead to a serious underestimate of the welfare gains arising from the introduction of a new product.

Similarly, the use of conventional price indices, such as the Fisher Ideal and Tornqvist price indices, may lead to inaccurate estimates of the consumer surplus that arises from the introduction of a new good and/or the good's subsequent price decline. The accuracy of such methods will depend on how fast the marginal utility for a new good rises as the quantity consumed goes to zero. Figuring this out is part and parcel of the new goods problem. That is, what utility function or demand equation should be used for estimating the welfare associated with the introduction of a new good? In fact, it is shown here that in some cases an equivalent variation fails to exist. In these cases, the assumptions required for the theory underlying the Fisher Ideal and Tornqvist price indices are not satisfied. While this is not true for the case of computers, it is found to be true in the case of another important new good, electricity. To illustrate this, the technique for measuring the welfare gain from new goods is also applied to electricity. The welfare gain from the invention and price decline in electricity, as measured by the compensating variation, is found to be $92 \%$ of personal consumption expenditure.

Another example in the literature is the Goolsbee and Klenow (2006) study of the benefit to consumers of the internet. They estimate the demand for the internet by relating the time spent using the product to the opportunity cost of time, an approach which, they argue, makes sense since internet access is a good whose marginal cost consists almost solely of the leisure time spent by the consumer. They find very large welfare gains when taking a literal interpretation of the model's structure. This is due to the fact that in their specification the marginal utility of internet consumption approaches infinity as consumption goes to zero. To mitigate the impact of the zeroconsumption region of the utility function, they emphasize an alternative measure based upon a linearized leisure demand curve. Additionally, their setup requires the elasticity of substitution to be greater than one. This is satisfied in the data for internet consumption. But, it is not true for all products. A case in point is cellular telephones, which Hausman estimates to have an elasticity less than one.

Finally, Petrin (2002) considers, as an example, the introduction of the minivan to demonstrate a technique for estimating welfare gains in the absence of consumer-level data. He shows how information describing the purchasing habits of different demographic groups, in conjunction with market-level data, can be used as a suitable substitute for consumer-level data. In his discrete-choice analysis minivan consumption is a lumpy good, so the specification of the utility function is not central. ${ }^{1}$

\section{COMPUTERS}

Computers first became available in the United States in the 1950s but at prices so high and sizes so large that, for the most part, no individual would want to buy one. It was not until the early 1970s, with the invention of the microprocessor, that the first generation of microcomputers - computers that were small enough to fit on a desk and inexpensive enough to be owned by individuals - was born. Lasting from 1971 to 1976, this period was characterized by a growing interest in computers among engineers and hobbyists. The year 1977 marks the birth of the PC. The key difference between PCs and their microcomputer predecessors is the limited amount of expertise that the use of the former requires. In other words, PCs are computers that

1. Greenwood and Uysal (2005) model a world with lumpiness in consumption and many consumer goods. An increase in income or a fall in price leads to a shift in consumption along the extensive margin, as the set of goods consumed changes. The implications of indivisibilities in consumption have not been fully explored in the literature yet. 
are both small in size and user friendly to individuals with no technical training.

The first PC to be successfully mass produced was the Apple II. Released in June of 1977 it consisted of a microprocessor running at 1 $\mathrm{MHz}, 4 \mathrm{~kb}$ of random-access memory (RAM), no hard disk, and an audio cassette interface for program loading and data storage. The computer retailed at approximately $\$ 1,200$. Systems with larger amounts of RAM were also available up to a maximum of $48 \mathrm{~kb}$ and at a price of approximately $\$ 2,600$. Rapid technological progress led to consistent improvement in the Apple II following its release. For example, in 1978 the floppy disk drive peripheral became available. Far superior to cassettes, the addition of floppy disks greatly improved the quality of Apple II computing.

Since the introduction of the Apple II, rapid technological progress in computer development has fueled continual quality improvements and declining costs of production. Compared to the Apple II, today's computers are often equipped with multi-core processors running at over 3,000 $\mathrm{MHz}$, gigabytes of RAM, and hard drives capable of storing hundreds of gigabytes of data.

Quality improvements in computers and computer production have resulted in an enormous fall in quality-adjusted PC prices. In fact, prices have dropped at an astounding rate of $25 \%$ per year. Thus, a PC today is more than 700 times cheaper than one in 1977. Starting from virtually zero demand for computers in and preceding 1977, the fall in prices throughout the last 30 years has been synonymous with a rapid rise in demand. Figure 1 shows price and quantity indices for computers and computer peripherals for the period 1977-2004-see the Appendix for information on the data. As the demand for PCs rose, so did their share of total expenditure. Figure 2 shows computer's share of total expenditure since 1977. It rose from 0 in 1977 to more than $0.6 \%$ in 2004 .

\section{MODEL}

Consider an individual with income, $y$, that can be used to purchase general consumption goods, $c$, and computers, $n$. Computers are measured in some sort of standardized, qualityadjusted units and sell at a price of $p$ in terms of consumption. Let the person's tastes be described by

(1) $\theta U(c)+(1-\theta) V(n), \quad$ with $0<\theta<1$.
FIGURE 1

Price and Quantity Indices for Computers, Peripherals, and Software for the Years

1977-2004

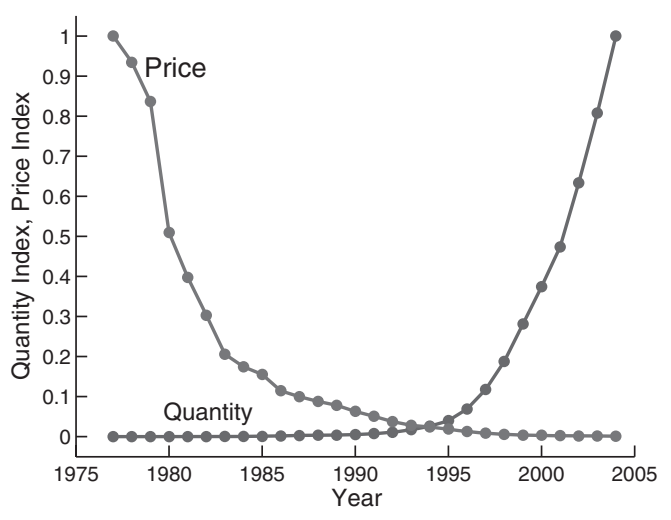

FIGURE 2

Computers, Peripherals, and Software's Share of Total Personal Consumption Expenditure for the Years 1977-2004

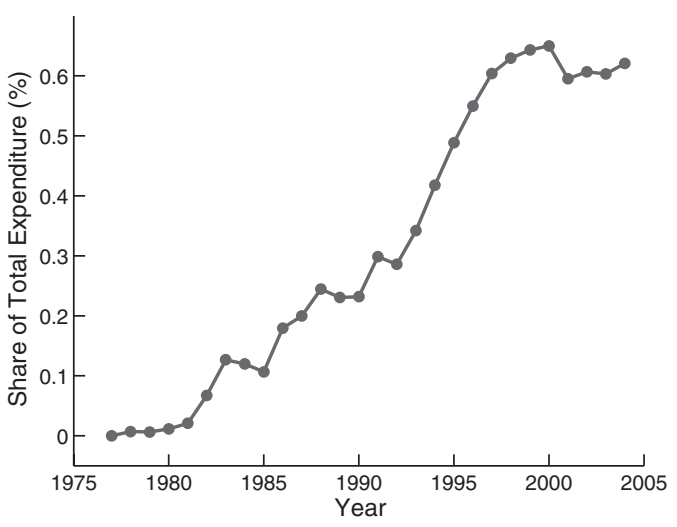

Take the utility function for the consumption of general goods to be of the standard constantrelative-risk-aversion variety, so that $U(c)$ can be written as

$$
U(c)=c^{1-\rho} /(1-\rho), \quad \text { with } \rho \geq 0 .
$$

Notice that $U(c)$ satisfies the standard properties $U_{1}(c)>0, U_{11}(c)<0, \lim _{c \rightarrow \infty} U_{1}(c)=0$, and $\lim _{c \rightarrow 0} U_{1}(c)=\infty$. Represent the utility function for PCs by

$$
V(n)=(n+\nu)^{1-\rho} /(1-\rho) \text {, with } 0<\nu<\infty \text {. }
$$




\section{FIGURE 3}

Tastes for Computers When $\rho \geq 1-$ Model and Conventional Formulation (dashed line)

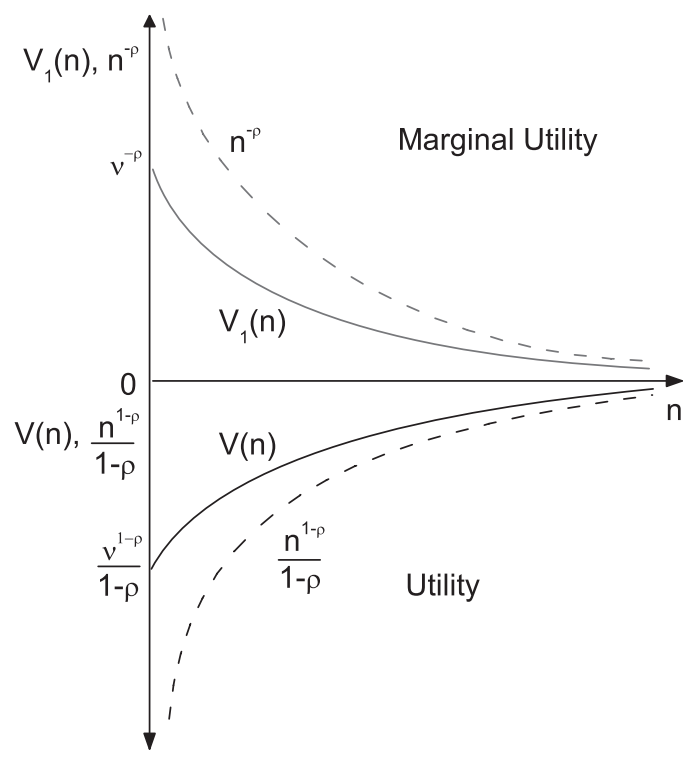

The function $V(n)$ is completely standard except that

$$
V(0)=v^{1-\rho} /(1-\rho)>-\infty \text { and } V_{1}(0)=v^{-\rho} \text {. }
$$

Observe that since $\rho \geq 0$, the magnitude of the elasticity of demand for computers is unrestricted. The implications of these assumptions on the utility function for PCs are portrayed in Figure 3, for the case where $\rho \geq$ 1. The conventional formulation is illustrated by the dashed line. Note that one could set $V(0)=0$ by redefining the utility function to be $\left[(n+\nu)^{1-\rho}-v^{1-\rho}\right] /(1-\rho)$; such a normalization has no implication for the analysis. Also, observe that the utility function for computers is nonhomothetic due to the presence of $\nu$.

The individual's static maximization problem will read

(4)

$$
w \equiv W(y, p)=\max _{c, n}[\theta U(c)+(1-\theta) V(n)],
$$

subject to his budget constraint

$$
c+p n=y,
$$

and the non-negativity conditions

$$
c, n \geq 0 \text {. }
$$

Note that $W(y, p)$ represents the person's indirect utility function, which gives his maximal level of welfare at the income level $y$ when he faces the price for computers $p$. The non-negativity constraint on $c$ will never bind and can be safely disregarded, because $\lim _{c \rightarrow 0} U_{1}(c)=\infty$. Since the marginal utility of zero computers is finite, the solution to the individual's maximization problem could be at a corner where $n=0$.

The solution to the above problem can be obtained by using the budget constraint (5) to substitute out for $c$ in the objective function (4) and then maximizing with respect to $n$. This leads to the Kuhn-Tucker conditions

(6)

$$
\begin{aligned}
& \theta(y-p n)^{-\rho} p-(1-\theta)(n+\nu)^{-\rho} \geq 0, \\
& n \geq 0, \\
& {\left[\theta(y-p n)^{-\rho} p-(1-\theta)(n+\nu)^{-\rho}\right] n=0 .}
\end{aligned}
$$

Equation (6), in conjunction with the budget constraint (5), determines the demand functions for $c$ and $n$ :

$$
\begin{aligned}
c & =C(y, p) \\
& =\left\{\begin{array}{l}
y, \\
\text { if } p \geq \widehat{P}(y) \equiv(1-\theta) / \theta \nu^{-\rho} y^{\rho} ; \\
(y+p \nu) /\left\{1+[(1-\theta) / \theta]^{1 / \rho} p^{(\rho-1) / \rho}\right\}, \\
\text { if } p<\widehat{P}(y),
\end{array}\right.
\end{aligned}
$$

and

$$
\begin{aligned}
n & =N(y, p) \\
& =\left\{\begin{array}{l}
0, \\
\text { if } p \geq \widehat{P}(y) ; \\
(y+p \nu) /\left\{p+[(1-\theta) / \theta]^{-1 / \rho} p^{1 / \rho}\right\}-\nu, \\
\text { if } p<\widehat{P}(y) .
\end{array}\right.
\end{aligned}
$$

Observe from Equation (8) that for any given income level, $y$, there exists a threshold price, $\widehat{P}(y)$, such that the optimal expenditure on computers will be zero whenever $p \geq \widehat{P}(y)$. The price $\widehat{P}(y)$ coincides with Hick's (1940) virtual price. It is the minimum price that sets the demand for $n$ equal to 0 , or is the price at which the demand curve for $n$ will touch the vertical axis. This threshold price is increasing in income. This implies that along a falling price path, the rich will buy the good before the poor do. Finally, note that the demand curve given by Equation (8) is not of a form that an applied economist would typically estimate. 
Last, suppose that computers can be produced from final output according to the production function

$$
n=z o \text {, }
$$

where $o$ is the use of output in computer production and $z$ is the level productivity in the computer sector. Under this assumption the price of computers is simply given by $p=1 / z$. Thus, the decline in the price of computers over time can be identified with exogenous technological progress in the production of computers. It is hard to comprehend how the observed astonishing $25 \%$ annual price decline can be anything else.

\section{A. Welfare Gain}

What is the welfare gain to consumers in 2004 from the invention of PCs and the fall in their relative price since 1977? The welfare gain will be measured in terms of both the equivalent and compensating variations.

First, suppose it is the year 2004 and computers have never been invented. As is readily apparent from Equation (8), this is the same as assuming that computers exist but sell at some prohibitively expensive price, say $p=\infty$. How much more income would you have to give to the consumer so that his welfare level without computers is equivalent to the one he obtained with them? This is the equivalent variation. Let $\lambda_{\mathrm{E} V}$ be the additional income required, measured as a percentage of actual 2004 income, $y_{2004}$. When computers do not exist the person will spend his entire income on the aggregate market good. His maximal utility will be

$$
\begin{aligned}
W( & \left.\left(1+\lambda_{\mathrm{E} V}\right) y_{2004}, \infty\right) \\
= & \theta\left(\left(1+\lambda_{\mathrm{E} V}\right) y_{2004}\right)^{1-\rho} \\
& /(1-\rho)+(1-\theta) \nu^{1-\rho} /(1-\rho) .
\end{aligned}
$$

In the year 2004 the consumer actually did purchase computers at the price $p_{2004}$. Assuming that he undertook his purchases optimally, his indirect utility function specifies a welfare level of $W\left(y_{2004}, p_{2004}\right)$.

The equivalent variation is determined, when it exists, by solving the following equation for $\lambda_{\mathrm{E} V}$ :

$$
\begin{aligned}
W\left(\left(1+\lambda_{\mathrm{E} V}\right) y_{2004}, \infty\right) & =W\left(y_{2004}, p_{2004}\right) \\
& \equiv w_{2004} .
\end{aligned}
$$

That is, the equivalent variation, $\lambda_{\mathrm{E} V}$, renders the individual indifferent between consuming $(1+\lambda) y_{2004}$ of the market good, $c$, and zero computers, on the one hand, and consuming his actual 2004 consumption bundle when computers exist and are available at 2004 prices, on the other. Equations (9) and (10) yield

$$
\begin{aligned}
\lambda_{\mathrm{E} V}= & {\left[(1-\rho) W\left(y_{2004}, p_{2004}\right)\right.} \\
& \left.-(1-\theta) \nu^{1-\rho}\right]^{1 /(1-\rho)} /\left(\theta^{1 /(1-\rho)} y_{2004}\right)-1 .
\end{aligned}
$$

Notice that the equivalent variation can be computed given data on total expenditures and prices, and estimates of the three preference parameters, $\nu, \theta$, and $\rho$.

The second measure of welfare that will be considered is the compensating variation. The compensating variation is similar to the equivalent variation. In fact, for quasi-linear preferences the two are equivalent. The compensating variation is the amount of income that would have to be taken from the consumer in 2004 to give him the level of welfare that he would have realized if computers had never been invented. Denote the compensating variation, measured as a percentage of the agent's 2004 income level, by $\lambda_{\mathrm{CV}}$. The compensating variation, $\lambda_{\mathrm{CV}}$, solves the equation

$$
W\left(\left(1-\lambda_{C V}\right) y_{2004}, p_{2004}\right)=W\left(y_{2004}, \infty\right) .
$$

Although $\lambda_{C V}$ cannot be written explicitly, it is uniquely defined by Equation (11) and can be computed numerically, given estimates of the preference parameters in conjunction with the data on prices and expenditures. ${ }^{2}$

\section{B. The Measurement of Welfare Gains Using Price Indices}

Approximations of the compensating and equivalent variations can be computed from a Tornqvist price index as follows. Define $E(w, p)$ to be the expenditure function associated with the welfare level $w$ and the price $p$.

2. In particular, note that

$$
\begin{aligned}
W( & \left.\left(1-\lambda_{\mathrm{CV}}\right) y_{2004}, p_{2004}\right) \\
= & {\left[C\left(\left(1-\lambda_{\mathrm{CV}}\right) y_{2004}, p_{2004}\right)\right]^{1-\rho} /(1-\rho) } \\
& +\left[N\left(\left(1-\lambda_{\mathrm{CV}}\right) y_{2004}, p_{2004}\right)+\nu\right]^{1-\rho} /(1-\rho),
\end{aligned}
$$

where the functions $C(\cdot)$ and $N(\cdot)$ are specified by (7) and (8). Also, recall that $W\left(y_{2004}, \infty\right)$ is given by (9), when $\lambda_{\mathrm{E} V}$ is set to zero. 
Thus

$$
E(w, p)=\min _{c, n}[c+p n],
$$

subject to

$$
\theta U(c)+(1-\theta) V(n)=w .
$$

Suppose that the expenditure function can be approximated by a translog function. Then, one can write

$$
\begin{aligned}
E(w, p) \simeq & \exp \left(\alpha+\beta \ln p+\kappa \ln p^{2}\right. \\
& \left.+\psi \ln w+\sigma \ln w^{2}+\mu \ln w \ln p\right) .
\end{aligned}
$$

Under this assumption, approximations of the equivalent and compensating variations of a price decline from $p_{1977}$ to $p_{2004}$ can be constructed from the Tornqvist price index, $P^{\mathrm{T}}$, using the formulae

$$
\lambda_{\mathrm{E} V}^{\mathrm{T}}=1 / P^{\mathrm{T}}-1 \text { and } \lambda_{\mathrm{C} V}^{\mathrm{T}}=1-P^{\mathrm{T}},
$$

where

$$
P^{\mathrm{T}} \equiv\left(p_{2004} / p_{1977}\right)^{\left(s_{1977}+s_{2004}\right) / 2},
$$

and

$$
s_{t} \equiv p_{t} n_{t} /\left(c_{t}+p_{t} n_{t}\right), \text { for } t=1977,2004 .
$$

(With some abuse of notation, in the discussion here think about $p_{1977}$ as representing the price of the new good in some initial period and $p_{2004}$ as giving the price in some final period, etc.) If $p_{1977}$ is Hick's (1940) virtual price at which demand is zero then $\lambda_{E V}^{T}$ and $\lambda_{C V}^{T}$ are approximations of the welfare gain from the introduction of the good and its subsequent price decline to $p_{2004}$. A magnificent discussion of the theory underlying this approach is given in Diewert (2008). Measures of the equivalent and compensating variation can also be constructed from the Fisher Ideal price index, at least when the expenditure function can be approximated by a quadratic function-again, see Diewert (2008). This works best when the utility function is homothetic, which it is not here.

Interestingly, there may not exist an equivalent variation large enough to compensate a person living today to forgo a new good. That is, there is no value for $\lambda_{\mathrm{E} V}$ that will solve (10).

LEMMA 1. (Nonexistence of an equivalent variation) Let tastes be given by Equations (2) and (3) and assume that $\rho \geq 1$. There are $p_{2004}, y_{2004}$, and $v$ combinations such that there does not exist a $\lambda_{\mathrm{E} V}$ that can satisfy (10); i.e., such that an equivalent variation does not exist.
Proof. See Appendix.

If the situation described in the Lemma happens, the assumptions underlying the theory justifying the use of price indices to measure welfare changes fail to hold. This occurs because, when the equivalent variation does not exist, the expenditure function cannot be well approximated by either quadratic or translog functions.

COROLLARY 1. (Nonexistence of a translog approximation) There are $p_{2004}, y_{2004}$, and $v$ combinations such that the expenditure function, $E(w, p)$, cannot be adequately approximated by either translog or quadratic functions.

Proof. Again, see Appendix.

REMARK 1. The argument can be extended to the case of a low initial demand at some high price. Set $p_{1977}$ at Hick's (1940) virtual price, $\widehat{P}\left(y_{2004}\right)$, so that $p_{1977}=\widehat{P}\left(y_{2004}\right)$. This is the minimum price that sets the demand for the new good equal to zero as defined in Equation (7). By continuity, when the equivalent variation does not exist, the expenditure function cannot be well approximated for any price $p<p_{1977}$ that is close enough in value to $p_{1977}$. But, for these $p$ 's, the demand for the new good, $N\left(y_{2004}, p\right)$, will be small but positive.

Even though the use of the Tornqvist price index to calculate measures of the welfare gains from new goods may work well in many situations, the above discussion is not merely a theoretical curiosity. As will be seen below, while the Tornqvist price index approach provides a reasonable approximation of the welfare gain from the introduction of computers, it does not work well for electricity.

\section{QUANTITATIVE EXPERIMENT}

The task is to compute the welfare gain to consumers in 2004 due to the invention of the PC in 1977 and the subsequent decline in its price. In order to compute this, information about appropriate values for the preference parameters must be obtained. There are three preference parameters to pin down: the coefficient of relative risk aversion, $\rho$, the weight on utility from aggregate market consumption net of computers, $\theta$, and the parameter $\nu$, which is important for specifying the marginal utility of zero computer consumption. These parameters 
are determined using the following calibration/estimation procedure.

To begin with, for each year $t$ between 1977 and 2004 let $\mathbf{p}_{t}$ represent the quality-adjusted price of computers relative to aggregate market consumption net of computers, and $\mathbf{y}_{t}$ denote total expenditure at date $t$ in the data. Similarly, let $\mathbf{n}_{t}$ be the aggregate quantity of qualityadjusted computers purchased. The price and expenditure data are taken from the Bureau of Economic Analysis (BEA) - see the Appendix for more detail. The BEA adjusts these series, using hedonic price methods and other techniques, for the quality improvement in computers, peripherals, and software that occurs over time. Out of the $16.5 \%$ annual decline in the quality-adjusted prices for PCs that occurred between 2001 and 2005, Wasshausen and Mouton (2006) report that $11.5 \%$ was due to quality adjustment and $4.9 \%$ was attributable to changes in unit value. Given the quality adjustment that the BEA does to the data, think about $\mathbf{n}_{t}$ as representing the quantity of computers denominated in some sort of standardized unit. Figure 1 shows the PC price and quantity indices. ${ }^{3}$

Next, note that given values for the preference parameters, the model's prediction for the quantity of computers consumed at some date $t, \widehat{\mathbf{n}}_{t}$, can be computed by plugging the corresponding price and income levels, $\mathbf{p}_{t}$ and $\mathbf{y}_{t}$, into the demand functions specified by (8) to obtain $\widehat{\mathbf{n}}_{t}=N\left(\mathbf{y}_{t}, \mathbf{p}_{t}\right)$. These demand functions also depend on the model's underlying parameters, $\rho, \theta$, and $\nu$. Denote this mapping from the preference parameters to the prediction for the quantity of computers consumed by $\widehat{\mathbf{n}}_{t}=\mathfrak{N}\left(\rho, \theta, \nu ; \mathbf{y}_{t}, \mathbf{p}_{t}\right)$.

Finally, the preference parameters are determined by minimizing the sum of the squares of the difference between the logarithm of the quantity of computers purchased as observed in the data and the logarithm of the quantity consumed as predicted by the model over the period 1977-2004. This estimation is undertaken subject to a constraint that is discussed now. The BEA reports that a zero quantity of computers (probably some trivial amount) was consumed

3. Berndt and Rappaport (2001) report quality-adjusted price declines for desktop and mobile PCs. For the period 1976-1999, they found that their prices fell somewhere between $25 \%$ and $27 \%$ a year. This is similar to the $25 \%$ calculated here using the BEA data for the period 1977-2004. Pakes (2003) finds that his hedonic index yields an average price decline of $16 \%$ for the 1995-1999 subperiod. This compares with $16 \%$ obtained using the BLS's hybrid method for the CPI and $22 \%$ for the PPI. in 1977 while they were available at a positive price. Very small amounts are reported in the years immediately after 1977. In order to track accurately the small amounts of computer consumption in the early years a restriction will be imposed on the estimation requiring that the predicted purchases of computer in 1977 must be zero. In other words, the parameters are chosen by solving

$$
\min _{\rho, \theta, v} \sum_{t=1977}^{2004}\left[\ln \mathbf{n}_{t}-\ln \mathfrak{N}\left(\rho, \theta, \nu ; \mathbf{y}_{t}, \mathbf{p}_{t}\right)\right]^{2},
$$

subject to

$$
\mathfrak{N}\left(\rho, \theta, v ; \mathbf{y}_{1977}, \mathbf{p}_{1977}\right)=0 .
$$

Essentially, one can think of the constraint as identifying $\nu$.

The calibration/estimation procedure results in a value for $\rho$ of 0.326 , a value for $\theta$ of 0.994 , and one for $v$ of $4 \times 10^{-5}$. The values are reasonable. The value for $\rho$ suggests that computers and general consumption goods are substitutes. This makes sense given that computers and their accessories have substituted for a variety of other goods such as calculators, typewriters, stationery, travel agents, photo albums, etc. At high levels of expenditure, the coefficient $1-\theta$ is approximately computer's share of total expenditure. In 2004 this was exactly 0.006 , so that the share of general goods in spending was 0.994 . Last, $\nu$ is only $0.005 \%$ of the quantity of computer purchases in 2004. The model's prediction for the logarithm of the quantity of computers demanded along with the logarithm of the quantity consumed from the data are given in Figure 4. As can be seen, the model fits the data remarkably well. The $R^{2}$ is 0.9813 .

Plugging the parameter values and the 2004 data into the formulas for the equivalent and compensating variations yields an equivalent variation of $2.14 \%$ and a compensating variation of $2.19 \%$. This compares with Hausman's (1996) estimate of $0.002 \%$ due to the introduction of Apple-Cinnamon Cheerios, which is a minor product innovation. Petrin (2002) reports a welfare gain of $0.029 \%$ associated with the advent of the minivan, a more substantive product. A much smaller fraction of the population owns minivans as compared with computers, though. Furthermore, this product has not seen the remarkable price decline that computers have. In a similar vein, Goolsbee and Petrin (2004) find a $0.035 \%$ gain tied to the genesis of satellite TV. The current estimate is far below 
FIGURE 4

Log (ln) Quantity Indexes for Computers, Peripherals, and Software for the Years 1977-2004

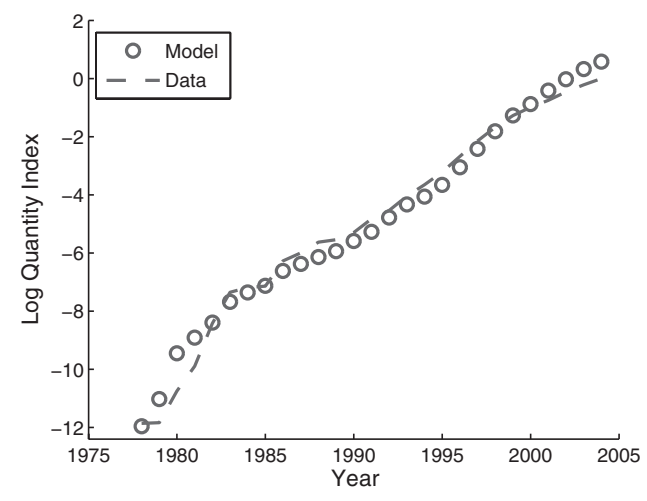

Goolsbee and Klenow's (2006) one of $26.8 \%$ resulting from the internet, at least when the model is interpreted literally. They note that with the isoelastic utility function they choose "the utility from the first units of consumption is so high" that the welfare gains will be large. ${ }^{4}$ As was mentioned, Goolsbee and Klenow (2006) present an alternative, smaller, estimate (their preferred one) based upon a linearized leisure demand curve to reduce the sensitivity of the welfare gain estimate to this region of the utility function.

Hausman's (1999) approximate demand measure of the welfare gain from the introduction of a new good is $0.5 \times$ (share of new good in expenditure)/(price elasticity of demand). The time series data for computer consumption suggest a price elasticity of 1.83 . This implies that

4. Modeling the consumption of internet services is trickier than other goods. Most consumers purchase internet services at a fixed monthly price. Therefore, they can use as much of the services in a month as they desire. The limiting factor is the amount of time that an individual wants to spend on the internet. This is why Goolsbee and Klenow (2006) estimate the demand for the internet by relating the time spent using the product to the opportunity cost of time. Modifying the utility function to bound the marginal utility of internet services at zero consumption would lower the welfare estimate. It should also help explain Goolsbee and Klenow's (2006) fact that $37 \%$ of people were not online. Putting more concavity in the utility function at high levels of consumption would help lower the welfare estimate as well. Last, as a technical aside, Goolsbee and Klenow (2006) mix internet consumption and time spent surfing in a Cobb-Douglas fashion. It would be an interesting exercise to remodel things with a Leontief structure, because this would explicitly bind internet consumption by the time devoted to it. a $10 \%$ increase in the quality-adjusted price of computers will result in an $18 \%$ decrease in demand. Taking their 2004 expenditure share of 0.006 (one of the larger values recorded as can be seen from Figure 2) suggests a welfare gain of only $0.16 \%$. As was mentioned, Hausman (1999) states that his approximate demand measure is best interpreted as a lower bound on the welfare gain. It is a far cry from the true value that obtains if tastes take the form specified in (1) with the estimated parameter values. The small number obtained from Hausman's approximation procedure results from the fact that computers constitute a small share of expenditure. Yet, they still are important in generating utility. His linear demand approximation method is likely to perform better for the introduction of more minor products, such as AppleCinnamon Cheerios, which can be viewed as a small change from the status quo. In fact, Hausman's measure performs worse than the welfare measures obtained using the Tornqvist price index, as given by Equation (13). The index performs well yielding estimates of $2.07 \%$ and $2.03 \%$ for the equivalent and compensating variations respectively. The Fisher Ideal price index does not work well in this situation, yielding estimates of $137 \%$ and $58 \% .^{5}$

\section{A. Some Sensitivity Analysis}

Given the outstanding fit of the model to the data, room for an improved estimation would appear to be small. One could try generalizing the utility function over general goods consumption and computers. Specifically, assume that the utility functions for general goods consumption and computers have different degrees of curvature:

$$
\begin{aligned}
U(c, n) & =\theta c^{1-\rho} /(1-\rho)+(1-\theta) \\
& \times(n+\nu)^{1-\gamma} /(1-\gamma),
\end{aligned}
$$

with $0 \leq \theta \leq 1$ and $\rho, \gamma \geq 0$. Calibrating this modified version of the model using the procedure described above yields $\theta=0.97, \rho=1.8$, $\gamma=0.76$, and $\nu=4 \times 10^{-5}$. The equivalent and

5. This price index is the geometric mean of the Laspeyres and Paasche prices indices. The Laspeyres price index is given by $\left(c_{1977}+p_{2004} n_{1977}\right) /\left(c_{1977}+\right.$ $\left.p_{2004} n_{1977}\right)=1$, because the initial consumption of computers is zero so that $n_{1977}=0$. The Paasche index is defined as $\left(c_{2004}+p_{2004} n_{2004}\right) /\left(c_{2004}+p_{1997} n_{2004}\right)$, which is a small number given the rapid decline in the price of computers; i.e., $p_{1997}$ is very high relative to $p_{2004}$. Thus, the Fisher Ideal price index shows an extremely steep decline. 
compensating variations under this version of the model turn out to be $3.3 \%$ and $3.2 \%$ of 2004 consumption, respectively. The upshot of the above analysis is that it may be best to view the welfare gain from PCs as lying in the range of $2.14 \%-3.3 \%$.

One can also compute the welfare gain that computers generated at any year from the time of their introduction in 1977 to 2004, using the estimated parameter values and the price and quantity data. The average welfare gains for each year, computed as the average of the equivalent and compensating variations generated from both versions of the model, are plotted in Figure 5. It is possible that there is some error in the measurement of the qualityadjusted prices for PCs. Thus, it is interesting to assess the sensitivity of the welfare estimates to variations in the observed rate of price decline. Using the price data to compute a 95\% confidence interval around the mean annual rate of price decline generates a lower bound for the price decline of $23 \%$ and an upper bound of $26 \%$. Now, construct two rescaled price series that have average rates of decline that are consistent with these bounds; i.e., just multiply the period- $t$ price for computers by $(1.23 / 1.25)^{t-1977}$ and $(1.26 / 1.25)^{t-1977}$. Corresponding lower and upper bounds on the welfare estimates can then be computed, using these two rescaled price series. These bounds on the welfare estimates are also presented in Figure 5. Notice how the welfare benefit grows over time as the price for computers declines. Brynjolfsson (1996) estimates that the welfare gain from computers was somewhere between $0.2 \%$ and $0.3 \%$

\section{FIGURE 5}

\section{Year-by-Year Welfare Gains for Personal} Computers

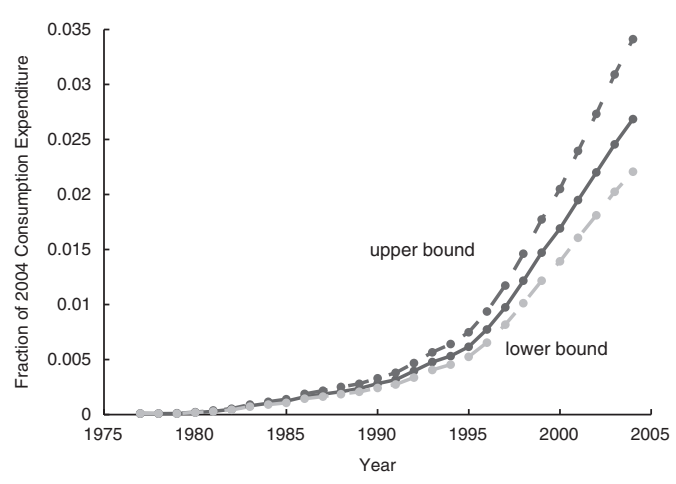

of gross domestic product (GDP) in 1987. This compares with the $0.2 \%$ found here. ${ }^{6}$

The analysis above shows that a simple model of a representative consumer with a slight modification to the standard isoelastic utility function can lead, using a straightforward calibration/estimation procedure and aggregate data, to a reasonable measure of the welfare gain realized from the introduction of PCs. A few words of caution are in order, however. First, since the parameter values are not determined through a statistical estimation, the analysis is silent on standard errors and other tests of the model. Second, the welfare measures are conditional on the parametric form chosen for utility. This is a problem that many econometric approaches suffer from as well. On the latter point, there may be nonseparabilities in utility between computers and other specific goods. For example, Gloosbee and Klenow (2006) assume that internet services and leisure are EdgeworthPareto complements in the utility function. This could be true of computers more generally, of course. Think about playing computer games. Internet services could also be an EdgeworthPareto substitute with housework, if they can be used to reduce time spent on chores such as paying bills, shopping, etc. Gloosbee and Klenow (2006) also mention that there may be spillover effects across consumers that are important for household computer adoption. Entering a network externality into tastes may provide another route for modeling the low initial demand for computers. More sophisticated specifications of tastes would probably require more data in order to estimate the structure well, such as the timeuse data used by Gloosbee and Klenow (2006).

\section{ELECTRICITY, ANOTHER NEW GOOD}

The method outlined above is a reasonable and simple way to estimate the welfare gain from the invention of, and advancements in, major new goods whose price decreases over time are primarily driven by technological progress. One of the most important innovations in modern history is electricity. Following the approach that is used for computers, the welfare gain is computed from the invention of electricity and the subsequent technological improvements that led to a decrease in its price. The

6. Brynjolfsson (1996) discusses several measures of consumer welfare, such as the Hicksian and Marshallian notions of consumer surplus. They all give more or less the same answer. 
model with electricity is calibrated using price and expenditure data for electricity taken from the BEA - details are provided in the Appendix. Prices are available for each year from 1929 to 2006. At the first available price observation the quantity of electricity consumed was far from zero, unlike in the case for computers. In fact, electricity was already approximately $0.8 \%$ of total consumption expenditure in 1929 , more than half of its 2006 level of $1.6 \%$. Consequently, the price that sets demand to zero, which was used earlier to identify the parameter $\nu$, is not the 1929 price nor any of the other prices observed over the 1929-2006 period. Thus, the calibration is carried out exactly as in the computer case, but without any constraint on the demand function.

The procedure generates a value for $\rho$ of 9.26 , a value for $\theta$ of $1-10^{-8}$, and a value for $\nu$ of 0.062 . The high value of $\rho$ means that general consumption goods and electricity are strong complements in utility. This makes sense given that, for the most part, people do not derive utility from electricity alone but by combining electricity with other consumption goods. As with computers, the model is able to do a good job of matching the demand for electricity observed in the data. The $R^{2}$ is 0.9776 .

The compensating variation computed from the model for electricity is $92.0 \%$ of total 2006 consumption expenditure. How does this compare to Hausman's (1999) approximate demand measure? Reiss and White (2005) estimate the price elasticity of demand for electricity in California to be 0.39 . Plugging this plus electricity's share of expenditure in 2006, $1.6 \%$, into Hausman's formula results in a welfare gain of only $2.0 \%$. According to Reiss and White (2005), a lower bound on the price elasticity based on other studies is 0.15 . Electricity's share of expenditure over the 1920-2006 period was the highest in 1984 when it reached 2.4\%. Using these extreme values, Hausman's measure generates a welfare gain of $8.0 \%$.

Measures of the welfare gain arising from the introduction of electricity can also be computed using the Tornqvist price index. To do this, use the model to compute Hicks (1940) virtual price; that is, the minimum price that sets the demand for electricity equal to zero. Suppose that this was the price of electricity in 1881, the year when the Niagara Falls Hydraulic Power \& Manufacturing Company opened a small power station that generated a small amount of electricity to light the village of
Niagara Falls. This price can then be plugged into the Tornqvist price index. The estimates of the compensating and equivalent variations derived from the Tornqvist price index are $22.8 \%$ and $29.6 \%$, respectively. ${ }^{7}$ Even though the Tornqvist price index performs much better than Hausman's measure, the resulting estimate for the compensating variation is still a long way from the $92.0 \%$ welfare gain generated by the model.

In line with Lemma 1, there does not exist an equivalent variation large enough to compensate a person living in 2006 to forgo electricity. That is, there is no value for $\lambda_{\mathrm{EV}}$ that will solve (10). This illustrates that it may not be possible to give people enough income in 1881 (the equivalent variation) to make them as well off living then without electricity (the new good) as they do today with it. That is, individuals cannot obtain enough utility from the "old goods" to compensate them for the loss of the "new good." This makes intuitive sense. On the other hand, it is always possible to take enough income away from someone today (the compensating variation) to make him/her as bad off as an individual living in 1881. For example, think about taking away all of his income. He would then be worse off than someone living in 1881 .

Last, Figure 6 shows the plot of the equivalent variation, based on the estimated values for $\theta, \rho$, and $\nu$, as the price for electricity rises from some conjectured initial starting value, denoted by $p$, toward the virtual price $P\left(y_{2006}\right)$. The final price is the 2006 price for computers. Observe that the equivalent variation grows without bound. The figure also shows the plot of the Tornqvist approximation to the equivalent variation. As the initial price for electricity becomes large the gap between the two measures widens.

An interesting application of the technique developed here is undertaken in Hersh and Voth (2009). They estimate the welfare gains from the introduction of new products in the 17th century, namely coffee, sugar, tea, and tobacco. While today's consumer takes these simple goods for granted, life was Spartan at that time. The consumption basket was weighted heavily toward

7. Specifically, the welfare gains are given by (13) with

$$
P^{\mathrm{T}}=\left[p_{2006} / \widehat{P}\left(y_{2006}\right)\right]^{s_{2006} / 2},
$$

where $p_{2006}, y_{2006}$, and $s_{2006}$ are electricity's price, income, and expenditure share in the 2006 U.S. data and where the virtual price $\widehat{P}\left(y_{2006}\right)$ is defined in (7). 
FIGURE 6

The Equivalent Variation and Its Tornqvist Approximation

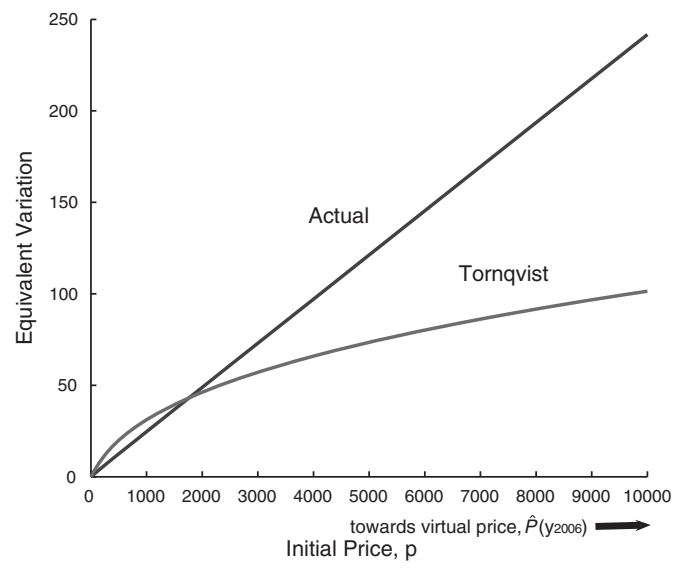

food. The European diet was essentially composed of beer, grains, meat, milk, and water. Hersh and Voth (2009) discuss how these new goods dramatically transformed European eating habits. After their introduction, the price of goods such as sugar and tea declined rapidly [see Hersh and Voth (2009, figures 2-4)]. They estimate that by 1850 the introduction of tea and sugar alone was worth about $15 \%$ of consumption to the average consumer.

\section{CONCLUSION}

What is your PC worth to you? About $2 \%-3 \%$ of total consumption expenditure is the finding. This answer is predicated upon a simple model of consumer demand. A slight modification of the standard isoelastic variety of preferences results in a well-behaved demand for computers: demand drops to zero as prices rise to some well-defined level, and the consumer's surplus associated with a new good is generally bounded. The model of consumer demand is fit to national income and product data, using a straightforward calibration/estimation procedure, to uncover the taste parameters needed for the welfare analysis. The parameter values obtained are reasonable and the framework fits the aggregate data well. In addition, the results are robust to a modification of preferences. Finally, the method for computing the welfare gain for computers is found to work well for estimating the welfare gain from electricity. In this case the theoretical assumptions required for price indices to approximate the gain in welfare are violated. Here, a compensating variation of $92 \%$ is found. No equivalent variation exists, implying that it would be impossible to compensate a person living today to go without electricity.

\section{APPENDIX}

\section{Theory}

Proof of Lemma. First, suppose that

$$
w_{2004} \equiv W\left(y_{2004}, p_{2004}\right)>(1-\theta) \nu^{1-\rho} /(1-\rho) .
$$

When this transpires an equivalent variation cannot exist because the right-hand side of Equation (9) approaches $(1-\theta) \nu^{1-\rho} /(1-\rho)$ from below as $\lambda \rightarrow \infty$. But $W\left(y_{2004}\right.$, $\left.p_{2004}\right)>(1-\theta) \nu^{1-\rho} /(1-\rho)$, by assumption. Second, there exists a $v$ such that (A1) holds. To see this, note that $(1-\theta) \nu^{1-\rho} /(1-\rho) \rightarrow-\infty$ as $\nu \rightarrow 0$. Now, with a little effort, it can be shown that when both goods are consumed

$$
\begin{aligned}
W\left(y_{2004}, p_{2004}\right) \\
=\left(y_{2004}+p_{2004} \nu\right)^{1-\rho} /(1-\rho) \\
\times\left[1 /\left[1+\left(\frac{1-\theta}{\theta}\right)^{1 / \rho}\left(p_{2004}\right)^{(\rho-1) / \rho}\right]\right]^{1-\rho} \\
\times\left[\theta+(1-\theta)\left[((1-\theta) / \theta)\left(1 / p_{2004}\right)\right]^{(1-\rho) / \rho}\right] .
\end{aligned}
$$

By picking $p_{2004}$ and $y_{2004}$ appropriately this expression can be clearly made bigger than $(1-\theta) \nu^{1-\rho} /(1-\rho)$. There are many combinations that can do this. For example, $W\left(y_{2004}, p_{2004}\right) \rightarrow \theta\left(y_{2004}\right)^{1-\rho} /(1-\rho)$ as $p_{2004} \rightarrow 0$ So, pick $y_{2004}>[(1-\theta) / \theta]^{1 /(1-\rho)} v$ for some small $p_{2004}$.

Proof of Corollary. In line with the lemma, pick combinations for $p_{2004}, y_{2004}$, and $v$ such that an equivalent variation does not exist. Now, suppose that the expenditure function can be approximated by a translog function in line with (12). Under this assumption, the equivalent variation of a price decline from Hick's (1940) virtual price $p^{*} \equiv \widehat{P}\left(y_{2004}\right)$ to $p_{2004}$ is given by

$$
\begin{aligned}
\lambda_{\mathrm{E} V}= & E\left(w_{2004}, p^{*}\right) / y_{2004}-1 \\
\simeq & {\left[\alpha+\beta \ln p^{*}+\kappa \ln \left(p^{*}\right)^{2}+\psi \ln w_{2004}\right.} \\
& \left.+\sigma \ln w_{2004}^{2}+\mu \ln w_{2004} \ln p^{*}\right] / y_{2004}-1 .
\end{aligned}
$$

Clearly, $\lambda_{\mathrm{E} V}$ given by the formula above is finite, a contradiction. The argument for the quadratic function is the same.

\section{Data}

All the computer data derives from the U.S. National Income and Product Accounts, Tables 2.4.4 and 2.4.5, and spans the period 1977-2004. The electricity data is from the same source; however, it spans the period 1929-2006. These tables are available on the website for the BEA. When mapping the model into the computer data, the variable $n$ is taken to be real personal consumption expenditure on 
computers, peripherals, and software. This series is constructed by deflating nominal personal consumption expenditure on computers, peripherals, and software by the price index for this particular series. Note that BEA adjusts these series, using hedonic price methods and other techniques, for the quality improvement in computers, peripherals, and software that occurs over time. The variable $c$ represents real personal consumption expenditure on all other goods. This is obtained by subtracting nominal personal consumption expenditure on computers, peripherals, and software from total nominal personal consumption expenditure, and then deflating by the price series for personal consumption expenditure. The relative price $p$ is simply taken to be the ratio of the price index for personal consumption expenditure on computers, peripherals, and software to the price index for personal consumption expenditure. Last, real income, $y$, is simply defined by $y=c+p n$, which is total personal consumption expenditure.

The mapping from the model to the data for the case of electricity is done in exactly the same ways as for computers. The only difference is that instead of expenditure and prices for computers, peripherals, and software, the variables $n$ and $p$ are taken to be real personal consumption expenditure and prices for electricity services, respectively.

\section{REFERENCES}

Berndt, E. R., and N. J. Rappaport. "Price and Quality of Desktop and Mobile Personal Computers: A QuarterCentury Historical Overview." American Economic Review, 91(2), 2001, 268-73.

Brynjolfsson, E. "The Contribution of Information Technology to Consumer Welfare." Information Systems Research, 7(3), 1996, 281-300.

Diewert, E. W. "Consumer Surplus and the Measurement of Ex Post Welfare Change.” Economics 581: Lecture Notes, University of British Columbia, 2008.
Goolsbee, A., and P. J. Klenow. "Valuing Consumer Products by the Time Spent Using Them: An Application to the Internet." American Economic Review, 96(2), 2006, 108-13.

Goolsbee, A., and A. Petrin. "The Consumer Gains from Direct Broadcast Satellites and the Competition with Cable TV." Econometrica, 72(2), 2004, 351-81.

Greenwood, J., and G. Uysal. "New Goods and the Transition to a New Economy." Journal of Economic Growth, 10(2), 2005, 99-134.

Hausman, J. "Exact Consumer's Surplus and Deadweight Loss." American Economic Review, 71(4), 1981, $662-76$.

. "Valuation of New Goods under Perfect and Imperfect Competition," in The Economics of New Products, edited by T. Bresnahan and R. Gordon. Chicago: University of Chicago Press, 1996, 209-37.

- "Cellular Telephone, New Products, and the CPI." Journal of Business and Economic Statistics, 17(2), 1999, 188-94.

Hersh, J., and H. J. Voth. "Sweet Diversity: Colonial Goods and the Rise of European Living Standards after 1492." Mimeo, Department of Economics, Universitat Pompeu Fabra, 2009.

Hicks, J. R. "The Valuation of the Social Income." Economica, 7(2), 1940, 105-24.

Pakes, A. "A Reconsideration of Hedonic Price Indexes with an Application to PCs." American Economic Review, 93(3), 2003, 1578-96.

Petrin, A. "Quantifying the Benefits of New Products: The Case of the Minivan." Journal of Political Economy, 110(4), 2002, 705-29.

Reiss, P. C., and M. W. White. "Household Electricity Demand, Revisited." Review of Economic Studies, 72(3), 2005, 853-83.

Wasshausen, D., and B. R. Mouton, "The Role of Hedonic Methods in Measuring Real GDP in the United States." Mimeo, Bureau of Economic Analysis, U.S. Department of Commerce, 2006. 